\title{
Special issue: international conference on applied system innovation (ICASI 2018)
}

\author{
Sheng-Joue Young ${ }^{1} \cdot$ Teen-Hang Meen ${ }^{1} \cdot$ Ajit Khosla $^{2}$ (D) $\cdot$ B. Michel ${ }^{3}$
}

Published online: 15 June 2020

(C) Springer-Verlag GmbH Germany, part of Springer Nature 2020

The IEEE International Conference on Applied System Innovation (ICASI) 2018 was successfully held on April 13-17, 2018, at Chiba, Japan. ICASI provides a communication bridge for researchers worldwide and enables international and interdisciplinary collaborations between science and engineering technologists in the academic, industrial, and networking fields. ICASI 2018 covered a wide range of topics, including information science, innovation design, industrial design, applied mathematics, computer science, cultural and creative research, electrical and electronic engineering, mechanical engineering, automation engineering, green technology and architectural engineering, material science, and other related fields.

This special issue presents more than 50 excellent papers selected from ICASI 2018 that cover a wide range of fundamental studies, industrial practices, and engineering innovations by applying knowledge on microsystems. Engineering and design innovations are academic and practical engineering fields that involve systematic technological materialization through scientific principles and engineering designs. Technological innovation by electri$\mathrm{cal} / \mathrm{mechanical}$ engineering includes information technology (IT)-based intelligent electrical/mechanical systems,

\footnotetext{
Ajit Khosla

khosla@gmail.com

Sheng-Joue Young

shengjoueyoung@gmail.com

Teen-Hang Meen

thmeen@nfu.edu.tw

B. Michel

bernd.michel@coinn.de

1 Department of Electronic Engineering, National Formosa University, Yunlin 632, Taiwan

2 Faculty of Engineering, Yamagata University, 4-3-16 Jonan, Yonezawa 992-8510, Yamagata, Japan

3 Fraunhofer Micro Materials Center Berlin, Berlin, Germany
}

electronics, mechanics, human-computer interaction, and design innovations. IT-based intelligent systems, which implant intelligence to systems, is an interdisciplinary area combining conventional electrical/mechanical technology and new IT. Internet of things (IOT) has also gained popularity in recent years. In fact, this special issue collected many IOT-related studies, such as those on sensors, electronics, software, and connectivity, which enable objects to connect and exchange data.

All articles in this issue underwent rigorous peer reviews conducted by Microsystem Technologies. The acceptance of this special issue was based on recommendations of the reviewers, mandatory revisions, final examinations, and reviews conducted by the guest editors. This publication is expected to be a key issue for Microsystem Technologies.

The guest editors would like to thank the authors for their contributions and all the reviewers for their constructive comments. Moreover, we would like to give special thanks to the Editor-in-Chief, Prof. Bernd Michel, for his generous support in the publication of this issue. Finally, we would like to thank the editorial team for their work in making this special issue a success.

We look forward to your participation in future special issues of Applied System Innovation.

Publisher's Note Springer Nature remains neutral with regard to jurisdictional claims in published maps and institutional affiliations. 